\title{
Resiliência e pandemia da Covid-19: análise em uma operadora de turismo à luz da teoria do ciclo de vida das organizações
}

\section{Resilience and Covid-19 pandemic: analysis in a tour operator in the light of the organizational life cycle theory}

Tatiana Gehlen Marodin ${ }^{1 *}$ Ernestina Alzira Floriano de Oliveira Prata, ${ }^{1}$, Marlei Salete Mecca ${ }^{1}$

\section{RESUMO}

O objetivo é apresentar como a resiliência promoveu a manutenção e/ou evolução nas fases do Ciclo de Vida das Organizações, durante a pandemia da Covid-19. Foi realizado um estudo de caso em uma operadora de Turismo localizada na região Nordeste do Brasil. Utilizou-se de método indutivo. Fez-se uso de estudo de caso com a realização de entrevista estruturada e análise de conteúdo; quanto aos objetivos a pesquisa é descritiva com abordagem qualitativa. Como principais resultados, durante a pandemia da Covid-19, houve queda drástica no faturamento da operadora em estudo. A operadora criou três produtos que foram responsáveis pela manutenção e sobrevivência da empresa. O "Voucher Onda Verde", o Feirão on-line e o Resort Sertanejo. Esses produtos foram responsáveis pelo cumprimento das metas de vendas do mês de junho de 2020 até o mês de janeiro de 2021. É possível identificar ações que retratam a resiliência onde a empresa evoluiu para a sexta fase do ciclo de vida das organizações de Greiner, contemplando soluções extraorganizacionais, que leva ao conceito de empresa "estendida", para além das suas fronteiras internas, envolvendo alianças, parceiros e participações diversas.

Palavras-chave: Ciclo de vida das organizações; Pandemia da Covid-19; Resiliência; Turismo.

\footnotetext{
${ }^{1}$ Universidade de Caxias do Sul - UCS

* E-mail: tatianagehlen@hotmail.com
} 


\begin{abstract}
The aim is to present how resilience promoted the maintenance and/ or evolution in the phases of the organizational life cycle, during the Covid-19 pandemic. A case study was carried out in a tourism operator located in the Northeast region of Brazil. An inductive method was used. A case study was used with a structured interview and content analysis. As for the objectives, the research is descriptive with a qualitative approach. As main results, during the Covid-19 pandemic, there was a drastic drop in the revenue of the operator under study. The operator created three products that were responsible for the maintenance and survival of the company. The "Voucher Onda Verde" (Green Wave Voucher), the Feirão on-line (on-line Market) and the Resort Sertanejo (Country Resort). These products were responsible for meeting the sales targets from June 2020 to January 2021. It is possible to identify actions that portray the resilience where the company evolved to the sixth phase of the Greiner's organizational life cycle, contemplating extraorganizational solutions, which leads to the concept of an "extended" company beyond its internal borders, involving alliances, partners, and several participations.
\end{abstract}

Keywords: Organizational life cycle; Covid-19 pandemic; Resilience; Tourism.

\title{
INTRODUÇÃO
}

Diante do cenário atual que se apresenta no mundo, encontram-se diversas incertezas, e uma delas versa sobre o futuro das organizações. Algumas lições aprendidas no passado, que até algumas décadas poderiam ser considerados verdadeiros axiomas, deixaram de ter efeito. Novos conceitos e contextos exigiram a adoção de novas práticas, no âmbito das organizações, dentre as quais a sustentabilidade sob novos enfoques.

O modelo de gestão mais eficaz deve contemplar em seu planejamento a resiliência como meio de garantir a perpetuação dos negócios no ciclo de vida das organizações. A respeito desse assunto, Denhardt e Denhardt (2010) afirmam que a resiliência pode ser entendida como uma característica de objetos ou materiais, indivíduos, organizações e sistemas. No campo das Ciências Humanas, a resiliência apresenta polissemia, e é concebida como uma trajetória, um contínuo, um sistema, um traço, um processo, um ciclo ou, ainda, uma categoria qualitativa conforme afirmam Flach (1991) e Rutter (1985).

Para Reich, Zautra e Hall (2010), a resiliência pode ser analisada em níveis diversos: dimensões básicas como a biológica, a cognitiva, a emocional, a comportamental; a perspectiva das fases da vida humana, a dimensão social e a 
organizacional ou da comunidade; e sob a ótica de aspectos étnicos e de diferentes dimensões culturais.

Dessa forma, entende-se que a utilização da resiliência nas organizações pode promover à sustentabilidade e proporcionar maiores possibilidades para que as organizações transponham as crises e evoluam no ciclo das organizações com maior longevidade. Dentro dessa perspectiva, diversos estudos têm apontado uma estreita relação entre esse binômio para perpetuação das organizações, neste momento presente de grandes adversidades e mudanças. Nesse sentido, o objetivo da pesquisa é apresentar de que forma a resiliência promoveu a manutenção e/ou evolução nas fases do Ciclo de Vida das Organizações durante a crise da pandemia da Covid-19.

Para tal, foi realizado um estudo de caso, em uma operadora de Turismo localizada na região Nordeste do Brasil. A referida operadora foi referência na região pelo enfrentamento às intempéries do mercado na crise da pandemia da Covid -19. Para atingir o objetivo utilizou-se de pesquisa descritiva - com estudo de caso - e, entrevista estruturada com análise de conteúdo e abordagem qualitativa.

Assim, esta pesquisa é um convite para um olhar teórico e reflexivo, a partir das contribuições dos autores mencionados, pois revelam argumentos importantes para aplicabilidade da resiliência e sustentabilidade, nas organizações em tempos de constantes mudanças e que podem ser identificados no estudo de caso apresentado.

\section{REVISÃO DA LITERATURA}

\section{Resiliência organizacional}

A resiliência não é vista sob o prisma individual, mas como a solução e o enfoque organizacional de promover as habilidades necessárias capazes de gerir os ciclos de mudanças com eficácia. Nesse sentido Horne e Orr (2011) afirmam que a resiliência de um sistema é uma abordagem conceitual utilizada na ecologia, que se refere à capacidade de os sistemas naturais se recuperarem de pressões ambientais, de tal forma que a sustentabilidade do sistema não seja comprometida. Westley et al. (2002, p.104) ponderam que a habilidade de construir significado permite que organizações (de pessoas) modifiquem a configuração (do sistema) e “[...] virem de um tipo de organização para outro tipo e de volta ao tipo inicial”. A capacidade de transformação e readaptação diante das adversidades se realizam a partir da resiliência e da sustentabilidade. 
Os autores Youssef e Luthans (2007), Masten e Wright (2010) e Denhardt e Denhardt (2010), reforçam essa ideia de que a recuperação, a adaptação positiva à adversidade e sustentabilidade do equilíbrio (físico e emocional e sistêmico) são elementos do conceito de resiliência.

Coutu (2002) e Hamel e Valikangas (2003) entendem a definição de resiliência organizacional como a habilidade de uma organização em desenvolver respostas situacionais às rupturas que representem ameaças potenciais à sua sobrevivência, que possibilitem, na verdade, que a organização capitalize desenvolvimento em tais situações, engajando-se em atividades transformadoras e restauradoras de sua capacidade responsiva.

As organizações, muitas vezes, precisam ter capacidade de gerir situações que estão fora do seu controle, como crises que afetam a saúde das organizações e diretamente os postos de trabalho dos seus colaboradores. Isso comprova que a sustentabilidade das organizações não se opera da mesma forma que no passado. Segundo Belinky e Vendramini (2017), a história da sustentabilidade empresarial revela que os comportamentos das organizações se adequam às pressões do contexto e o que funcionou em uma situação passa a não mais servir em outro.

No que diz respeito a esses fatores exógenos, a capacidade de superar crises, precipuamente àqueles causados por fatores externos, do qual não se pode controlar, nem sequer evitar, deve ser mediada com sabedoria e, porque não dizer utilizando a expressão mais correta da resiliência.

Davoudi et al. (2012) afirmam que ser resiliente, no sentido empresarial, é saber recuperar o equilíbrio após uma perturbação, e, também, encontrar novos equilíbrios. As crises proporcionam situações que desencadeiam transtornos de diversas ordens. Nesse sentido, torna-se imperativo aprender a sobreviver, ultrapassar os aspectos negativos e, utilizar a criatividade e expertise para criar alternativas viáveis que garantam a sobrevivência dos negócios e a qualidade de vida de todas as pessoas envolvidas neste processo. 
Diante de tantas incertezas - principalmente no cenário atual - o único meio ideal para transpor as barreiras e garantir a sobrevivência das organizações é a reafirmação dos propósitos e fazer uso da resiliência de forma evolutiva.

Sob esta ótica Abdulkareem e Elkadi (2018) defendem que a resiliência pode tanto estar ancorada na engenharia - com o sentido de capacidade de retorno ao estado original ou de manutenção da estabilidade frente ao estresse - quanto em uma perspectiva ecológica - em que resiliente é o sistema que recupera o equilíbrio após uma perturbação - ou sistêmica - relacionada à capacidade do sistema de manter seu desenvolvimento, encontrando novos equilíbrios.

A noção de resiliência evolucionária, proposta por Davoudi et al. (2012), incorpora a adaptabilidade como uma característica necessária aos sistemas para que sejam capazes de avançar em ciclos contínuos de inovação, transformação e reorganização diante de distúrbios frequentes e de magnitude estrutural.

Assim, para atravessar esse processo profundo de mudanças, propõe-se adotar novos princípios e estratégias para superação das adversidades. Nesse sentido, defendem Salter e Kothari (2016) que o processo de aprendizagem organizacional requer oportunidade de experimentação sem a pressão por resultados de curto prazo, além do registro dos aprendizados em base acessível, alimentando a memória organizacional e a construção de entendimentos comuns sobre conceitos e diretrizes.

Monzoni e Carvalho (2020) relatam que a humanidade vive hoje um contexto de extremas incertezas e instabilidades, em que forças de manutenção, de adaptação e transformação operam simultaneamente e pressionam empresas a lidar com elas, percebendo-as ou não, seja de maneira integrada e simultânea ou fragmentada e pontual. Uma das poucas certezas na crise atual é de que a reconstrução para melhor Building Back Better (BBB) descarta o retorno ao estado de onde se partiu e, portanto o favorecimento da força de manutenção; não apenas porque é impossível reconstituí-lo, mas também por estarem lá as causas do colapso.

\section{A dimensão da pandemia da Covid-19 no setor do turismo}


A história recente do Turismo Mundial é afetada, frequentemente, por várias crises econômicas ou sanitárias. Guerras, atentados, desastres naturais como inundações, furacões, incêndios e epidemias acabam afetando uma zona ou outra do planeta, onde deixam, por um tempo, essa zona restrita ao acesso dos turistas.

Em 2003, na reunião do Conselho Mundial do Turismo em Portugal, o tema geral do encontro era a saída da crise mundial do turismo que acumulava prejuízos com os atentados de 11 de setembro de 2001, a retração econômica mundial naquele então, as consequências da guerra do Iraque e da epidemia da SARS (RATTNER, 2003). Mal sabiam os envolvidos que ainda estava por vir o furacão Katrina ocorrido em 2005 nos Estados Unidos que devastou a cidade de Nova Orleans, a crise cambial de 2008, a gripe suína (H1N1) de 2009, a erupção do vulcão Eyjafjallajökul, em 2010, na Islândia, e a gripe aviária (H7N9) de 2013, apenas para citar algumas crises. Somente a título de exemplo Nova Orleans, nos Estados Unidos, levou mais de 10 anos para que a cidade pudesse receber o mesmo número de turistas que recebia antes do fenômeno (MOREIRA, 2015).

Outro exemplo, de como o turismo se comporta em tempos de crise ocorreu em 2008, durante a crise cambial. Houve uma desaceleração do crescimento de chegadas e partidas internacionais de turistas, quando comparado a 2007. Em 2007, o crescimento foi de 7\% e em 2008 foi de 2\% (MTur, 2009).

De todos os exemplos citados anteriormente, vale ressaltar que as chegadas e partidas internacionais não pararam por completo em nível mundial e praticamente todas as fronteiras se mantiveram abertas. Evidente que em um dado momento, um país teve mais cancelamentos de voos do que outro, ou atividades turísticas foram suspensas, mas nada se compara com a crise sanitária da Covid-19. Na verdade, no momento da escrita desta pesquisa ainda é prematuro dimensionar o tamanho das consequências desta crise sanitária, econômica e social, além das mudanças que vai ocasionar no mundo.

Segundo o The New York Times, (2020 apud BARBOSA, 2020) na análise da Pew Research Center, "93\% da população mundial vive hoje em países que adotaram algum tipo de medida de restrição de viagem e 3 bilhões de pessoas ao redor do mundo vivem em países que fecharam totalmente as fronteiras para estrangeiros”. O Brasil está 
incluído entre os países que fecharam suas fronteiras terrestres e aéreas, com algumas exceções para residentes, cidadãos brasileiros entre outros.

Se por um lado a única estratégia para conter a pandemia é o isolamento social, e isso demonstrou bons resultados nos países que o adotaram, por outro para a economia teve um impacto devastador, e a atividade turística como um todo, por não ser considerada serviço essencial está entre aquelas que serão mais afetadas durante todo o tempo da pandemia.

De acordo com as previsões da Organização Mundial do Turismo (OMT), os segmentos que podem ajudar na recuperação econômica do turismo, no cenário pós pandemia, são atividades de turismo rural, turismo de natureza, turismo de bem-estar, ecoturismo, turismo de aventura e turismo Gastronômico (MTur, 2020).

A Organização Mundial da Saúde (WHO) (2019) definiu algumas recomendações antes de flexibilizar o isolamento social e a retomada das atividades, entre elas a turística: a) ter a transmissão do vírus sob controle b) possuir sistemas de saúde com capacidade de detectar, testar, isolar e tratar todas as pessoas com a Covid-19 e os seus contatos mais próximos; c) possuir controle de surtos em locais especiais, como instalações hospitalares; d) adotar medidas preventivas de controle em ambientes de trabalho, escolas e outros lugares onde as pessoas precisam ir e) possuir manejo adequado de possíveis novos casos importados $\mathrm{f}$ ) estar a comunidade informada e engajada com as medidas de higiene e as novas normas.

Seguindo as recomendações da WHO (2019), vários protocolos de segurança foram desenvolvidos por estados e municípios no Brasil, mas somente isso não garante a retomada das viagens e muitos turistas ainda precisam se sentir seguros para sair de casa.

Dados da "Segunda onda do Covid" (2021) apontam que o turismo brasileiro perdeu 110 mil vagas de trabalho em 2020, distribuídos em hotéis, agências de viagens e operadoras de turismo, os principais setores da atividade.

Em números de faturamento o setor perdeu 55,6 bilhões no ano de $2020 \mathrm{em}$ comparação com 2019. A receita final de $\mathrm{R} \$ 113,2$ bilhões foi a pior receita desde que começou a ser feito o levantamento da receita nacional em 2011. Ainda segundo a 
"Segunda onda da Covid" os empresários do turismo só acreditam em um início de recuperação quando a população tiver sido vacinada em massa. A "segunda onda" da Covid, ainda em andamento no período de escrita deste artigo, foi muito mais violenta do que a dita "primeira onda".

De janeiro a março de 2021, o Brasil registrou 195.848 mortes por Corona vírus, em face de 194.949 registradas no ano de 2020 (BARCELLOS, 2021). Diante desse número de mortes e o fechamento de atividades não essenciais em milhares de municípios brasileiros, o desenvolvimento da atividade turística ficou muito prejudicado.

\section{Dimensões de sustentabilidade em tempos de crise}

$\mathrm{Na}$ atualidade, não existe mais espaço para organizações que não se preocupam com modelos de gestão alinhados às propostas de desenvolvimento sustentável, observando os aspectos econômicos, sociais e ambientais através do paradigma do Triple Botton Line (TBL).

Antes da pandemia da Covid-19, Eisele, Petrini e Vaccaro (2015) já afirmavam que o posicionamento de mercado vinha sofrendo fortes impactos, tendo em vista as condições competitivas e os desafios para se tornar uma empresa sustentável. Diariamente, organizações necessitam desenvolver soluções inovadoras para se adequarem a noção de sustentabilidade. Nicoletti et al. (2020) afirmam, depois de uma análise feita em 13 empresas, durante o período inicial da Pandemia da Covid-19, que é imprescindível que as empresas adotem o princípio da adaptabilidade em seus processos de gestão. É importante que elas possam perceber as perturbações e se transformem por meio de processos de aprendizagem organizacional.

Em tempos de crise, como esse da Pandemia da Covid-19, inúmeras empresas foram fortemente afetadas em toda a sua estrutura, e muito mais do que se adequar ao conceito de sustentabilidade, tiveram que inovar para poder sobreviver. Moreira (2020) traz para a discussão, além de todos os aspectos de estudo ambiental, social e econômico, a premissa da ética. Ele afirma que quando se fala em empresa que se preocupa com a sua sustentabilidade está necessariamente falando de uma empresa ética. 
Lanzarini e Bodnar (2020, p. 136) comentam que se a empresa foi ética com seus colaboradores, então estes também saberão ajudar em tempos de recuperação, segundos autores:

(...) uma empresa que tenha se preocupado com a dimensão social da sustentabilidade, mantendo relações saudáveis com seus colaboradores, fornecedores e a sociedade em geral, por certo contará com a boa vontade destes na execução do plano de recuperação. $\mathrm{O}$ comprometimento dos empregados, bem como a confiança dos credores influenciará positivamente na consecução do pacto de reestruturação.

No princípio da Pandemia da Covid-19, mas especificamente nos meses de março, abril e maio de 2020, era quase impensável oferecer produtos e serviços turísticos quando milhares de pessoas já estavam morrendo de uma doença, que até o momento da escrita desse artigo não foi encontrada a cura. Por muitos, foi até mesmo considerado antiético a oferta de serviços de lazer quando muitas famílias eram obrigadas a lidar com o luto.

Por outro lado, a manutenção de milhares de empresas, sobretudo de empresas turísticas, era condição sine qua non para que não acontecessem fechamentos, como de fato ocorreram. A título de exemplificação, apenas no setor de operadoras de turismo, a Associação Brasileira das Operadoras de Turismo (BRAZTOA) constava com 92 associadas antes da Pandemia e em fevereiro de 2021 eram apenas 50 (BRAZTOA, 2021).

As dimensões sociais, econômicas e ambientais, propostas pela abordagem do TBL precisam se relacionar de tal forma que a intersecção das três possa resultar em sustentabilidade da empresa. Em tempos de crise, é fundamental reforçar que somado às dimensões é fundamental reforçar o princípio da ética, para que o comércio de bens e serviços não seja feito sem qualquer critério, apenas pensando em criar fluxo de caixa, e sobrevivência da empresa.

Moreira (2020) traz para a discussão, principalmente, pelo mundo ainda se encontrar sob os efeitos da pandemia, o princípio da solidariedade. Ele afirma que durante o processo da pandemia, foi necessário que as empresas e pessoas se reunissem pelo bem comum. Foi necessário a junção de grupos que encontraram soluções e criaram alternativas para passar pela crise. Os grupos que criaram soluções éticas contribuíram significativamente - para a manutenção de suas empresas e consequentemente por milhares de empregos. 


\section{Ciclo de vida das organizações}

Indivíduos, empresas, células, organismos vivos, dentre outros, passam por diferentes etapas ao longo de suas vidas. Cada uma dessas etapas pode ser chamada de fases e cada uma das fases possui características bem definidas e são consequências das modificações pelas quais as organizações passam ao longo do tempo.

Ao abordar o Ciclo de Vida das Organizações observa-se que as fases são identificadas quando são analisadas as capacidades cognitivas dos executivos, a estrutura da organização e os contextos nos quais elas operam. Todos os organismos vivos estão submetidos ao fenômeno de ciclo de vida, segundo Adizes (1998), da mesma forma, as organizações possuem um ciclo de vida no qual enfrentam os embates e as dificuldades normais de cada estágio, e, também, os problemas usuais de transição, ao ingressarem numa nova fase de desenvolvimento.

Os estágios de desenvolvimento do ciclo de vida de uma organização consistem, segundo Frohlich, Rossetto e Silva (2007), em um período com características próprias, e se definem na trajetória de vida de uma organização. Segundo os autores, estudos acerca desses estágios evidenciam que a postura da administração, geralmente desempenhada pelo empreendedor, visível através das práticas de gestão durante os estágios de desenvolvimento dos ciclos de vida das empresas, influencia as chances de sobrevivência dessas organizações. Segundo Hizon e Bronson (2004), cada fase do ciclo de vida das organizações exige a utilização de novas competências dos seus empreendedores bem como a utilização adequada de formas de tecnologia. De acordo com os autores, as organizações seguem essa abordagem com a intenção de renovar sua vantagem competitiva.

O modelo do Ciclo de Vida, para Pimenta e Borges (2006), é útil para entender a história e a evolução da empresa e os processos pelos quais vem passando ao longo do tempo. Os vários modelos existentes diferem pelo número de etapas de evolução e pela natureza das variáveis descritivas utilizadas. Geralmente, os estudos sobre os ciclos de vida organizacional têm como objetivo analisar a transição das organizações, focalizando, principalmente, as mudanças ocorridas na estrutura organizacional. Os modelos de Ciclo de Vida das Organizações são apresentados pelos autores Churchill e Lewis (1983), Scott 
e Bruce (1987), Kaufmann (1990), Adizes (1990; 2004), Macedo (1993), Marques (1994), Gersick et al. (1997), Greiner (1998) e Moreira (1999) e apresentam fases e etapas diferenciadas, porém com uma certa semelhança na forma de compreensão e análise.

Nesta pesquisa será utilizado o modelo do Ciclo de Vida das Organizações (CVO) proposto por Greiner. O modelo de CVO de Greiner (1998) compreende que a toda nova fase a organização passa por um período de evolução, com crescimento constante e estabilidade, e por fim com uma etapa mais turbulenta, apresentando uma crise de gestão, a revolução.

A presença do empreendedor é percebida claramente através de suas ações diretas, que podem ser notadas nas primeiras fases do ciclo, que são a criatividade e a direção. Na crise, necessária para a evolução da segunda para a terceira fase, é imprescindível que o empreendedor decida se quer uma empresa pequena ou grande, e é na transição da segunda para a terceira fase que a comunicação começa a ser informal e surge a delegação. O modelo de CVO preconizado por Greiner apresenta cinco fases, a saber: criatividade, direção, delegação, coordenação e colaboração, conforme a Figura 1.

Figura 1: Ciclo de Vida das Organizações

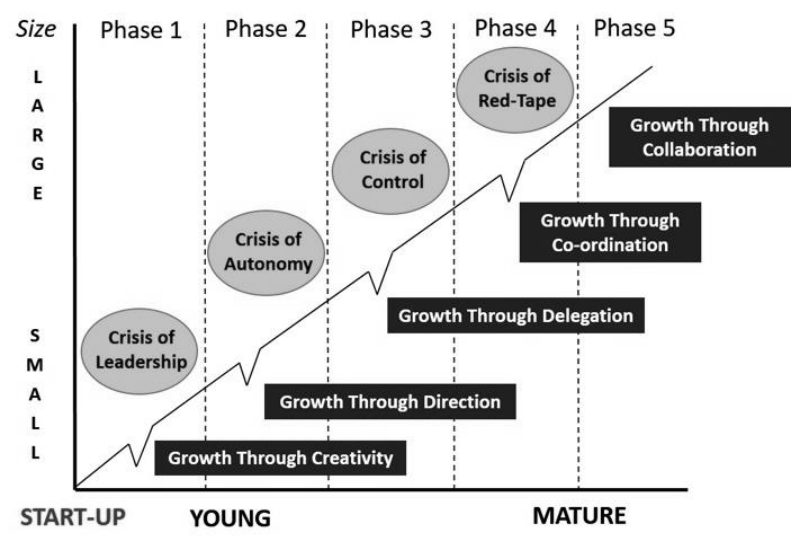

Fonte: adaptado de Greiner (1998)

$\mathrm{Na}$ fase de criatividade, a atenção está voltada para o produto e o mercado. As ações surgem em decorrência das reações dos clientes. Os empreendedores não focam nas atividades de gerenciamento e a comunicação interna flui de forma informal. Surgem 
a necessidade de controle financeiro e os conflitos relacionados com a liderança. Surge também - nesse momento - a necessidade de inserir na empresa um administrador de negócios que possa impulsionar o empreendimento.

$\mathrm{Na}$ fase da direção, a comunicação se torna ainda mais formal e impessoal. Surgem as departamentalizações, as áreas de comercialização e produção são definidas, ocasionando uma maior delegação de autoridade e responsabilidade. Surgem também os sistemas de controle contábil, financeiro e de produção. Tendo em vista o crescimento da empresa, surgem reclamações dos empregados por maior autonomia, o que cria a necessidade de delegar poder de decisão. Na fase da delegação, conforme Greiner (1998), a comunicação não é frequente e costuma-se utilizar correspondências e telefonemas. $\mathrm{O}$ processo de descentralização da estrutura organizacional tem presença forte nesta fase. É o momento em que o empreendedor precisa decidir se quer uma empresa pequena ou se prefere o crescimento da estrutura organizacional. Se optar pelo crescimento, será necessário desenvolver suas capacidades gerenciais.

$\mathrm{Na}$ fase da coordenação, os sistemas formais de gerenciamento darão suporte para assegurar a coordenação de tarefas entre as diferentes áreas. Com a necessidade de coordenar e acompanhar as atividades das áreas, surge a burocracia. As organizações cresceram e se tornaram complexas, os sistemas que dão suporte à coordenação das atividades acabam por inibir a inovação limitando a ação dos gerentes.

Segundo Grenier (1998), na fase de colaboração, é preciso resgatar a espontaneidade e o espírito empreendedor; os sistemas precisam ser simplificados e a resolução de problemas deve ser rápida e realizada em grupo, proporcionando o comprometimento interpessoal. Nessa fase, a sobrecarga de trabalho pode resultar em estresse. Dessa forma, é importante monitorar e identificar em que fase do ciclo de vida das organizações a empresa se encontra. Isso propicia o planejamento de como proceder diante das dificuldades decorrentes do processo de crescimento organizacional.

Mais recentemente Greiner (1998) apresenta a sexta fase como sendo de soluções extraorganizacionais, que contempla a criação de uma arquitetura de negócio, baseada numa holding e em uma rede que leva ao conceito de empresa "estendida", para além das suas fronteiras internas, envolvendo alianças, parceiros e participações diversas. 
Greiner (1998) ao apresentar o seu modelo de Ciclo de vida das Organizações, preconiza que a passagem ou evolução entre as diversas fases ocorre, com frequência, por crises. Essas crises fazem parte do processo de desenvolvimento das organizações e podem ocorrer repentinamente seja por fatores internos ou externos, como é o caso da pandemia da Covid-19. Greiner também aponta que as crises, se enfrentadas adequadamente e com resiliência, podem promover a passagem e a evolução das organizações.

\section{METODOLOGIA}

A pesquisa em estudo buscou identificar a resiliência em uma organização, durante a pandemia da Covid-19, utilizou-se de método indutivo que parte do conhecimento geral para entender algo específico. Dessa forma, utilizou-se, quanto aos procedimentos técnicos, de estudo de caso com a realização de entrevista estruturada e análise de conteúdo, em relação aos objetivos a pesquisa é descritiva e quanto à abordagem do problema é qualitativa.

Pesquisas que se utilizam de estudo de caso buscam refletir, segundo Mascarenhas (2018), sobre um conjunto de dados para descrever com profundidade o objeto de estudo, seja ele uma pessoa, uma família, uma empresa ou uma comunidade. O estudo de caso possibilita entender muito bem o contexto analisado. Utilizou-se de entrevista para coleta dos dados relacionados ao estudo de caso. A entrevista, conforme Mascarenhas (2018), é utilizada para levantar informações que não são encontradas em fontes bibliográficas, mas podem ser obtidas conversando com as pessoas. A entrevista estruturada ocorre através de um roteiro com perguntas previamente formuladas pelo pesquisador.

As informações coletadas na entrevista estruturada foram analisadas através de análise de conteúdo que, segundo Marconi e Lakatos (2017) levam em consideração o significado do conteúdo. Para Bardin (2016), análise de conteúdo trabalha com mensagens de comunicação e o objetivo da análise de conteúdo é a manipulação de mensagens, a fim de evidenciar indicadores que permitam inferir sobre outra realidade que não a da mensagem.

Em relação à pesquisa descritiva, segundo Michel (2015, p. 54) ela "tem o propósito de analisar, com a maior precisão possível, fatos ou fenômenos em sua natureza 
e características, procurando observar, registrar e analisar suas relações, conexões e interferências". Na concepção de Gil (2018), a pesquisa descritiva tem como principal objetivo descrever características de determinada população ou fenômeno ou o estabelecimento de relações entre as variáveis. Uma de suas características mais significativas está na utilização de técnicas padronizadas de coleta de dados.

Conforme Sampieri, Collado e Lucio (2013, p. 102) "a pesquisa descritiva busca especificar as propriedades, as características e os perfis de pessoas, grupos, comunidades, processos, objetos ou qualquer outro fenômeno que se submeta a uma análise". Ou seja, pretendem unicamente medir ou coletar informação de maneira independente ou conjunta sobre os conceitos ou as variáveis a que se referem, isto é, seu objetivo não é indicar como estas se relacionam.

Utilizou-se pesquisa qualitativa, pois esta possibilita uma análise mais profunda em relação ao fenômeno que está sendo pesquisado. De acordo com Yin (2016, p. 22) "a pesquisa qualitativa difere por sua capacidade de representar as visões e perspectivas dos participantes de um estudo". Capturar suas perspectivas pode ser um propósito importante de um estudo qualitativo. O principal objetivo da pesquisa qualitativa, segundo Michel (2015) não é mostrar opiniões ou pessoas. Em vez disso, pretende explorar a gama de pontos de vista e as diferentes representações do assunto em estudo. Para Richardson (2017), os estudos que empregam uma metodologia qualitativa podem descrever a complexidade de determinado problema, analisar a interação de certas variáveis, compreender e classificar processos dinâmicos vividos por grupos sociais. $\mathrm{O}$ autor destaca a profundidade, o entendimento das particularidades e do comportamento dos indivíduos.

Para a coleta de dados, utilizou-se de entrevista estruturada que foi realizada no dia 15 de abril de 2021 com um dos gestores da empresa em estudo. Na entrevista utilizouse de roteiro previamente elaborado com base no referencial teórico. A entrevista foi gravada, e, posteriormente transcrita pelos pesquisadores. Após a transcrição, ocorreu a análise dos dados coletados à luz das teorias que suportam a pesquisa.

\section{RESULTADOS E DISCUSSÃO}




\section{Relato de resiliência no enfretamento da crise da Covid-19 pela Foco Turismo Operadora.}

A empresa em estudo, a Foco Operadora Ltda, nasceu em setembro de 2009, tendo sido fundada a princípio por três sócios com o objetivo de trabalhar no mercado de operação turística e organização de eventos. Os sócios-fundadores haviam trabalhado por mais de dez anos em outra operadora turística sediada em Natal, RN, o que fez com que acumulassem experiência nesse segmento turístico, que trabalha diretamente com as agências de viagens.

Naquele momento, a empresa foi iniciada com dois computadores pessoais e duas escrivaninhas, sem nenhum capital inicial ou de giro, mas os sócios apostavam no conhecimento operacional e na rede de relacionamento já adquiridos em empresas anteriores, fatores fundamentais nesse ramo de negócios e chamado de capital social por Minarelli (2001).

O foco da empresa, no início das operações, foi serviços turísticos para o mercado nacional, principalmente para o Nordeste brasileiro, região da qual os sócios tinham expressiva experiência e conhecimento. Desse "foco" surgiu o nome da empresa que passou a ser chamar Foco Operadora. A empresa como não contava com capital, foi auxiliada por alguns clientes (agências de viagens) que patrocinaram passagens para o evento da Associação Brasileira dos Agentes de Viagens (ABAV) edição 2009, móveis de escritório, entre outras colaborações.

Durante a participação na ABAV/2009, um fornecedor do mercado receptivo da Serra Gaúcha ofereceu o patrocínio da inauguração da Foco Operadora em Natal, e tal evento contou com mais de 180 agentes de viagens confirmados. Nesse evento foram lançadas campanhas de vendas para o mercado gaúcho, o que foi fundamental para o início da empresa.

Para que uma operadora de turismo comece a funcionar, ela precisa ter autorização de "sinais", ou seja, acesso a sistemas de venda de hotelaria, passagens aéreas, transfers, seguros-viagens entre outros serviços. O início das atividades da Foco só foi possível graças à concessão do sinal por um operador do estado de Pernambuco que recebia um 
percentual de todas as vendas feitas pela Foco. Nesse momento, segundo Grenier (1998), a empresa encontra-se na fase de criatividade.

Depois de dois anos de funcionamento, em meados de 2011, a principal operadora turística existente em Natal encerrou suas atividades e toda a demanda de clientes foi migrada para a Foco, o que serviu para incremento das vendas e manutenção da empresa no mercado natalense. Durante esse período, a empresa já tinha feito acordos operacionais diretamente com as principais companhias aéreas, empresas de hotelaria e cruzeiros marítimos, o que deu maior agressividade às tarifas. Grenier (1998) conceitua essa fase como a fase de direção, anteriormente explicitada.

De acordo com o diretor comercial da empresa, um diferencial da Foco Operadora, no sentido da administração financeira, foi sempre o de efetuar pagamentos internacionais assim que recebesse o dinheiro do cliente para evitar as variações cambiais.

\section{Da fase de expansão e crescimento}

Após 6 anos de criação, a empresa criou um contrato de uso da marca para o estado da Paraíba. A Foco - naquele momento - absorveu os clientes que ficaram "órfãos" de uma antiga operadora. A concessão permitiu o uso da marca e o atendimento de agências de viagens, mas toda e qualquer questão financeira ficou centralizada em Natal, na empresa matriz. Foi aplicada a concessão do uso da marca como modelo de negócios, mas cada representante deveria possuir seu próprio CNPJ.

Em 2018, a Foco fez a mesma concessão de uso de marca para os mercados de Sergipe e de Alagoas. No final de 2019 concedeu o uso da marca para o estado do Ceará, que ainda sendo uma empresa iniciante teve que gerir as dificuldades trazidas pela Pandemia da Covid-19. Essa fase, chamada de fase de delegação por Grenier (1998) é bem evidente na estrutura da empresa, tendo em vista que a estrutura organizacional começa ser delegada em diferentes estados do Brasil.

Uma das principais dificuldades para manutenção e crescimento da empresa é a dificuldade que os clientes (agências de viagens) têm em se atualizar no comércio eletrônico. De acordo com o diretor, existe um posicionamento crítico em relação às 
compras via internet, um receio muito forte de que a atividade de agente de viagens deixe de existir, mas, infelizmente, segundo o diretor da Foco Operadora, não existe muito interesse por parte dos agentes de viagens em se atualizarem quanto às novas tecnologias. A disputa no mercado pelo consumidor final é muito grande entre as grandes Online Travel Agency (OTAs) o que faz com que o agente de viagens se sinta ameaçado pelas mesmas, sobretudo as internacionais. Guimarães e Menezes (2016, p. 10) comentam que "as OTAs entraram no mercado para competir com as demais empresas do ramo de turismo e as agências de turismo tradicionais passaram a ter novos desafios, diante dessa nova realidade".

O diretor da Foco reforçou algumas vezes, durante a entrevista, que os diretores sempre imaginaram que o maior desafio da empresa tinha sido a sua criação absolutamente sem capital inicial ou qualquer capital de giro, mas reforçou que o descrédito do agente de viagens trouxe muita preocupação para a empresa, porque o próprio cliente começava a não acreditar mais no agenciamento tradicional. Havia uma resistência muito grande em se adaptar às novas tecnologias.

\section{Consequências da Pandemia da Covid-19}

No dia $1^{\circ}$ de abril de 2020, o estado do Rio Grande do Norte, através do Decreto $\mathrm{n}^{\mathrm{o}} 29.583$ suspendeu todas as atividades de pessoas jurídicas que utilizassem sistema artificial de circulação de ar, por ar-condicionado, ou similar. Diante desde decreto a Foco Operadora interrompeu as atividades presenciais e todos os colaboradores foram orientados a continuar trabalhando de suas residências, através do trabalho remoto.

Essas medidas, que não foram diferentes em outros estados do país, assustaram os consumidores que viram empresas fechadas, hospitais sobrecarregados e as companhias aéreas cancelando - diariamente - diversos voos. Essa situação teve um impacto muito forte nas vendas da empresa. Para que se tenha uma ideia, o faturamento da empresa Foco em fevereiro de 2020 era de aproximadamente R \$1.000.000,00/mês e nos meses de abril e maio foi de apenas $\mathrm{R} \$ 20.000,00 /$ mês.

Nesse momento, em que pode ser chamado de inovação em tempos de crise segundo Dosi (1988), a Foco teve que criar um produto que pudesse ser comercializado para gerar fluxo de caixa. O diretor comercial juntamente com seu sócio e os 
colaboradores criaram o Pacote Anticorona. Esse pacote Anticorona foi resultado de tarifas muito competitivas acordadas com apenas duas pousadas situadas em São Miguel do Gostoso, RN. O cliente poderia utilizar o voucher até um ano depois da data da compra, sempre em baixa estação com exceção de feriados. Em contrapartida, a Foco Operadora enviaria o valor recebido do cliente imediatamente para a Pousada. É importante salientar que a prática normal das operadoras é sempre repassar os valores para hotéis e pousadas depois da saída dos hóspedes.

A princípio essa ideia foi muito criticada pelos agentes de viagem e hoteleiros porque associava o nome do vírus a um produto de lazer. $\mathrm{O}$ descrédito também com futuras vendas era bastante comum junto aos agentes, segundo o diretor. Em alguns dias, o produto começou a ter boa aceitação pelo consumidor final e a despertar interesse de hoteleiros que estavam com seus índices de ocupação abaixo de $20 \%$. O produto Pacote Anticorona teve a adesão inicial de 02 meios de hospedagens e dentro de poucas semanas já existiam mais de 50 fornecedores interessados em fazer parte dessa nova ideia. Diante das críticas recebidas, a Foco entendeu que precisaria mudar o nome do produto e passou a chamar "Voucher Onda Verde".

O cenário de negócios no começo da pandemia, principalmente para os pequenos agentes de viagens, era de desolação. Sem perspectiva de reabertura do mercado, oferecer serviços de viagens era quase uma afronta ao cliente final. O número de mortes começou a aumentar consideravelmente no Brasil e os clientes recuaram em suas compras de lazer. Os que haviam comprado passeios, voos e hospedagem procuravam as agências para cancelar.

As pequenas agências, naquele momento, entre março e maio de 2020, tinham paralisado quase que por completo suas atividades e estavam muito desestimuladas, algumas inclusive informando que iriam encerrar suas atividades. Segundo o diretor de marketing da Foco Operadora, esse cenário foi fundamental para reconhecer que os agentes de viagem precisavam mudar o processo de comunicação com o seu cliente final. A Associação Brasileira das Operadoras de Turismo (BRAZTOA) (2021) informou em seu anuário que o faturamento das operadoras de turismo associadas a Braztoa 2020 foi 67\% menor do que em 2019. 
Após a criação do Pacote Anticorona, posteriormente renomeado para o Voucher Onda Verde, a empresa resolveu criar uma estratégia de vendas denominada Feirão On Line. Nesse novo formato de vendas, a operadora convidou todas as agências de viagens cadastradas junto à operadora e essas puderam convidar os seus clientes (consumidores finais) para participar do Feirão.

Esse $1^{\circ}$ Feirão On Line aconteceu no dia 18 de junho de 2020 contou com a participação de mais de 90 agências de viagens e aproximadamente 40 fornecedores. $\mathrm{O}$ Feirão foi realizado através do Canal do You Tube Operadora, e na verdade, foi uma espécie de Feira de Negócios, que já acontecia todos os anos de forma presencial, mas desta feita, ocorreu virtualmente. O diferencial nesse momento foi o convite aos clientes finais.

É importante ressaltar que esse processo não é muito fácil de ser operacionalizado porque existe uma desconfiança muito grande das agências de viagens em exporem os seus clientes para a concorrência ou para a própria operadora. Geralmente, esse mercado de agentes de viagens é altamente competitivo, então o receio de ter o cliente "roubado" por outra agência é muito grande. Todo o trabalho de divulgação do Feirão On Line teve o cuidado de enfatizar a questão ética onde o cliente só poderia comprar os produtos comercializados, durante o Feirão através da agência de viagens.

Após a realização do o $1^{\circ}$ Feirão On Line com vendas bastante expressivas, a Operadora criou um produto denominado "Resort Sertanejo". As vendas foram lançadas em 2020 para eventos que acontecerão a partir do segundo semestre de 2021. A ideia consiste na contratação de cantores sertanejos ou de Música Popular Brasileira, considerados da "Velha Guarda" e organizar a apresentação do show dentro de um resort em regime all inclusive, ou seja, em um ambiente controlado, com medidas de higiene e protocolos da Covid-19. As principais características desse produto foram a limitação da quantidade de participantes já que apenas os hóspedes podem participar, a realização dos shows ao ar livre nas dependências do hotel e cada família poderá ser acomodada em uma mesa individual sem o contato com outros hóspedes.

De acordo com relatos do diretor da operadora, as vendas de vouchers livres geraram um valor aproximado de $\mathrm{R} \$ 300,00$ por voucher vendido e com a 
comercialização do produto "Resort Sertanejo" passaram para o valor de $\mathrm{R} \$ 4.000,00$ por pacote comercializado. Esse incremento no valor das vendas teve reflexo significativo no faturamento da operadora e das agências de viagem. Ainda segundo relatos do diretor, a criação do voucher Onda Verde e do $1^{\circ}$ Feirão On Line foram responsáveis pela operadora alcançar as metas de vendas do mês de junho de 2020 até o mês de janeiro de 2021. Apesar da crise financeira trazida pela pandemia, as metas de venda não foram reduzidas.

Perguntado ao diretor o que ele entende por resiliência este afirmou que as dificuldades trazidas pela pandemia, diferentes de qualquer outra crise que o setor já tinha passado, fez com que a empresa planejasse estratégias virtuais para atendimento dos clientes e isso contribuiu para que a empresa chegasse a vender mais do que o período anterior à pandemia. $\mathrm{O}$ não desistir, o se permitir errar e o acreditar, foram as palavras que o entrevistado definiu a resiliência para a empresa. $\mathrm{O}$ diretor fez um comentário interessante que merece ser transcrito: "Quando foi decretado o estado de pandemia não adiantava ir ao Google e pesquisar: Como manter a empresa aberta durante a pandemia da Covid-19?". Essa frase ele disse fazendo referência a que hoje quase todas as respostas estão no Google, mas a Pandemia era a situação mais difícil e diferente pela qual ele já tinha passado no setor do turismo nos últimos vinte anos. Nas palavras do diretor ele acredita que o fato de a empresa ser pequena e regional deu maior mobilidade na criação de novos produtos já que esta não precisa de aprovações e discussões da "Matriz" o que, muitas vezes, acontece em empresas de grande porte.

Durante todo o período da pandemia e até o momento da entrevista, a empresa demitiu apenas um colaborador e contratou dois, diferente do cenário de outras empresas do turismo conforme Oliveira (2021) que foram demitidos mais de 397 mil vagas de empregos formais no setor de operadoras e agências. Se for contar o impacto indireto chega-se a 1 milhão de empregos.

A entrevista ocorreu no dia 15 de abril de 2021, momento em que o Brasil passava duramente pela chamada "Segunda Onda" da pandemia com mais de 2.500 mortes diárias no país. Nesse momento, novamente os consumidores se retraíram nas compras e a Foco Operadora achou oportuno lançar o $2^{\circ}$ Feirão On Line que aconteceu no dia 30 de abril de 2021. Esse feirão teve a adesão de uma cia aérea que ofereceu duas trocas de data sem custo na contratação do pacote aéreo com hotel. Nesse momento, mais importante do que 
valores baratos é a questão da flexibilidade de datas, para que o consumidor final possa viajar em um momento em que os casos de Covid-19 estejam desacelerados ou sob controle relatou o diretor.

\section{CONCLUSÃO}

A pandemia da Covid-19 trouxe um cenário de adversidade para o mercado turístico como nunca vivenciado no setor. Cancelamentos de voos, reservas hoteleiras, passeios e serviços foram situações muito comuns pelos mais diversos países do mundo. A questão do cancelamento desses serviços turísticos, foi no começo da decretação da pandemia, uma situação muito difícil, porque além das operadoras e agências não estarem vendendo, eram obrigadas a reembolsar os clientes.

Em qualquer setor do comércio onde não se gera fluxo de caixa, torna-se improvável a sobrevivência da empresa em questão de poucos meses. A situação foi tão diversa que a resiliência - nas organizações - somada à criatividade foram fundamentais, na retomada de algumas empresas. A operadora Foco Turismo, objeto de estudo deste artigo, foi muito resiliente em manter a empresa funcionando e para que as vendas fossem mantidas um produto novo deveria ser criado.

A estratégia de utilização do voucher dentro do período de um ano após a compra foi capaz de manter pelo menos três players do mercado. A operadora que criou o produto, a agência que vendeu o serviço e o hotel ou fornecedor que recebeu os valores. Além disso, a operadora precisou trabalhar com a desconfiança dos seus clientes, com a baixa autoestima dos agentes de viagem e com a incerteza do cenário totalmente desconhecido.

Pode-se concluir, de acordo com as palavras do próprio diretor de marketing da empresa, que a rapidez na criação dos novos produtos, como o voucher Onda Verde, o Resort Sertanejo e o Feirão On Line, só foi possível tendo em vista a empresa ser de pequeno porte, comparada a outras operadoras do mercado nacional e por ter a autonomia de decisões. Caso fosse uma empresa grande, onde processos de decisões precisam ser tomados depois de várias reuniões em departamentos diferentes, talvez não tivessem tido sucesso. A resiliência organizacional foi colocada em prova no seu mais alto grau de deformação dentro da Foco Operadora, e ainda está sendo durante a escrita desta pesquisa, 
porém pode-se perceber que a proatividade, criatividade e enfrentamento de crises têm mostrado resultados positivos.

Como sugestão de estudos futuros poderia ser feito uma pesquisa de como foram os próximos meses de vendas e a criação de novos produtos até a decretação do final de estado de pandemia, oxalá em um futuro bem próximo.

\section{REFERÊNCIAS}

ABDULKAREEM, M.; ELKADI, H. From engineering to evolutionary, an overarching approach in identifying the resilience of urban design to ood. International Jornal of Disaster Risk Reduct, v. 28, p. 176-190, 2018.

ADIZES, I. Os ciclos de vida das organizações: como e por que as empresas crescem e morrem e o que fazer a respeito. São Paulo: Pioneira, 1990.

ADIZES, I. Os ciclos de vida das organizações: como e por que as empresas crescem e morrem e o que fazer a respeito. $4^{\mathrm{a}}$ ed. São Paulo: Pioneira, 1998.

ADIZES, I. Os Ciclos de Vida das Organizações: como e por que as organizações crescem e morrem e o que fazer a respeito. São Paulo: Pioneira Thomson Learning, 2004.

BARBOSA, L. G.M. (coord.) Impacto Econômico do COVID-19: propostas para o turismo brasileiro. fgvprojetos.fgv.br, abr. 2020

BARCELLOS, R. Números de mortes por Covid-19 no Brasil em 2021 já supera todo o ano de 2020. CNN Brasil, 5 abr 2021.

BARDIN, L. Análise de conteúdo. São Paulo: Edições, 2006.

BRAZTOA. Anuário 2021. São Paulo: BRAZTOA, 2021.

CHURCHILL, N. C.; LEWIS, V. L. Growing Concerns - Topics of particular interest to owners and managers of smaller businesses. Harvard Business Review, Watertown, p. 30-50, mai-jun. 1983

COUTU, D. L (2002). How resilience works. Harvard business review, maio, 2002.

DAVOUDI, S., et al. . Resilience: A Bridging Concept or a Dead End? "Reframing" Resilience: Challenges for Planning Theory and Practice Interacting Traps: Resilience Assessment of a Pasture Management System in Northern Afghanistan Urban Resilience: What Does it Mean in Planning Practice? Resilience as a Useful Concept for Climate Change Adaptation? The Politics of Resilience for Planning: A Cautionary

Note. Planning Theory \& Practice, v. 13, n.2, p. 299-333, 2012 
DENHARDT, J.; DENHARDT, R. Building organizational resilience and adaptive management. In: REICH, J. W.; ZAUTRA, A. J.; HALL, J. S. Handbook of adult resilience. New York, London: The Guilford Press, 2010, p. 333-349.

DOSI, G. The nature of the innovative process. In: DOSI, G. et al (org.). Technical change and economic theory. London: Pinter Publishers, 1998, p. 221-238.

EISELE, F.V.P. PETRINI, M. C. VACCARO, G. L. R. Inovação sustentável na cadeia suprimentos do plástico verde a partir da ótica do Ciclo de vida do produto. In:

CONGRESSO LATINO-IBEROAMERICANO DE GESTÃO DE TECNOLOGIA, 16., Porto Alegre. Anais[...] out., 2015

FLACH, F. Resiliência: a arte de ser flexível. São Paulo, SP: Saraiva, 1991.

FROHLICH, L.; ROSSETO C. R.; SILVA, A. B. Implicações das práticas de gestão no ciclo de vida organizacional. Análise, v. 18, p. 139-160. jan/jun, 2007.

GERSICK, K. et al. De geração para geração: ciclo de vida das empresas familiares. São Paulo: Negócio Editora, 1997.

GREINER, L. E. Evolution and revolution as organizations grow. Harvard Business Review, v. 76, n. 3. p. 55-68, 1998.

GIL, A. C. Como elaborar Projetos de Pesquisa. 6a ed - São Paulo: Atlas, 2018.

GUIMARAES. M. G. e MENEZES, V. O. O mercado de agência de viagens no Brasil e a influência da internet: as agências tradicionais e agências on line. Revista Turydes: Turismo y Desarollo v. 20, jun, 2016.

HAMEL, G., VALIKANGAS, L. The quest for resilience. Harvard Business Review. sep. 2003

HIZON, M. I. R.; BRONSON, J. W.; DOUGAN, W. L. The role of technology as a competitive weapon in each of the five phases of growth. ANNUAL USASBE NATIONAL CONFERENCE PROCEEDINGS. 18., 2004, jan. Dallas Texas, [Anais...] Dallas Texas, 2004, p. 15-18.

HORNE, J. F.; ORR, J. E. Assessing behaviors that create resilient organizations. Employment Relations, v. 24, n. 4, p. 29-39, 2011.

KAUFMANN, L. Passaporte para o ano 2000: como desenvolver e explorar a capacidade empreendedora para crescer com sucesso até o ano 2000. São Paulo: Makron- McGraw-Hill, 1990.

LANZARINI, C. A. BODNAR, Z. A Sustentabilidade Empresarial como Crédito Normativo à efetividade do Instituto da Recuperação Judicial. Scientia Iuris, Londrina, v. 24, n. 1, p. 124-141, jun. 2020. 
MARCONI, M. A.; LAKATOS, E. M. Metodologia do trabalho científico: projetos de pesquisa / pesquisa bibliográfica/ teses de doutorado, dissertações de mestrado, trabalhos de conclusão de curso. $8^{\mathrm{a}}$ ed. São Paulo: Atlas, 2017.

MARQUES, A. C. F. Deterioração organizacional: como detectar e resolver problemas de deterioração e obsolescência organizacional. São Paulo: Makron Books, 1994

MASTEN, A. S.; WRIGHT, M. Resilience over the lifespan: developmental perspectives on resistance, recovery, and transformation. In: REICH, J. W.; ZAUTRA, A. J.; HALL, J. S. Handbook of adult resilience. New York, London: The Guilford Press, 2010, p 213-237.

MASCARENHAS, S. Metodologia Científica. $2^{\mathrm{a}}$ ed. São Paulo: Pearson Education do Brasil, 2018.

MICHEL, M. H. Metodologia e pesquisa científica em ciências sociais: um guia prático para acompanhamento da disciplina e elaboração de trabalhos monográficos. $3^{\text {a }}$ ed. São Paulo: Atlas, 2015.

MINARELLI, J. A. Networking: como utilizar a rede de relacionamentos na sua vida e na sua carreira. São Paulo. Ed Gente, 2001.

MONZONI, M.; CARVALHO, A. Pós-Covid-19: reconstruir para melhor. gvexecutivo. v. 19, n. 3. p. 46-50, 2020.

MOREIRA, B. L. Ciclo de vida das empresas: uma análise do comportamento e desenvolvimento das organizações. São Paulo: STS, 1999.

MOREIRA, I. 7 Fatos que você precisa saber sobre o furacão Katrina. Revista Galileu, 24 ago. 2015.

MOREIRA, A.M.A. Ética empresarial e sustentabilidade em momentos de crise: uma análise sob a perspectiva do princípio da solidariedade. Revista de Direito e

Sustentabilidade, v. 6, n. 2, 2020

MTur. Ministério do Turismo do Brasil. Coronavírus - Esclarecimentos e informações para o setor de Turismo. Brasília: MTur, 2020.

MTur. Ministério do Turismo do Brasil. Informativo do MTur sobre a Organização Mundial do Turismo. $9^{\text {a }}$ ed. Brasília: MTur, 2009

NICOLETTI, M. et al. Atuação empresarial para sustentabilidade e resiliência no contexto da Covid-19. Scielo Brasil, v. 60, n. 6, nov-dec, 2020.

OLIVEIRA, J. J. Turismo demitiu 1 milhão na pandemia e só retoma em 2023, diz associação. Economia.uol.com.br, 20 fev. 2021.

PIMENTA, D. P., e BORGES, J. F. A relevância do processo sucessório para o ciclo de vida da pequena empresa familiar: o caso da CODEPE. In: SEMEAD: 
ADMINISTRAÇÃO NO CONTEXTO INTERNACIONAL, 9., 2006, São Paulo. [Anais...]. São Paulo: USP, 2006.

RATTNER, J. Sars pode eliminar 8 milhões de empregos no turismo mundial. BBCBrasil, 2003.

REICH, J. W.; ZAUTRA, A. J.; HALL, J. S. Handbook of adult resilience. New York, London: The Guilford Press, 2010, p. 213-237.

RICHARDSON R. J. Pesquisa Social: métodos e técnicas. $4^{\text {a }}$ ed. São Paulo: Atlas, 1999.

RUTTER, M. Resilience in the face of adversity: protective factors and resistance to psychiatric disorder. British Journal of Psychiatry, v. 147, n. 6, p. 598-611,1985.

SALTER, K. L., KOTHARI, A. Knowledge 'Translation' as social learning: Negotiating the uptake of research-based knowledge in practice. BMC Medical Education, v. 16, n. 76, p. 1-10, 2016.

SAMPIERI, R.; COLlADO C.; LUCIO, M. Metodologia de Pesquisa. $5^{\text {a }}$ ed. Porto Alegre: Penso, 2013

SEGUNDA onda de covid-19 faz turismo nacional perder quase um terço do faturamento de janeiro. fecomercio.com.br, 17 mar. 2021

SCOTT, M.; BRUCE, R. Five Stages of Growth in Small Business. Long Range Planning, v. 20, n. 3, p. 45-53, 1987

VENDRAMINI. A.; BELINKY, A. A nova fonte de valor econômico. gvexecutivo. v. 16, n. 5, p. 27-31, 2017.

WESTLEY et al (2002). Why systems of people and nature are not just social systems. In: GUNDERSON, L. H.; HOLLING, C. S. Panarchy: understanding transformations in human and natural systems. Washington, DC: Island Press, 2002, p. 103-119.

WHO. World Health Organization. Novel Coronavirus. Genebra: WHO, 2019.

YIN, R. Pesquisa qualitativa do início ao fim. Porto Alegre: Penso, 2016.

YOUSSEF, C.; LUTHANS, F. Positive organizational behavior in the workplace: the impact of hope, optimism, and resilience. Journal of Management, v. 33, n. 5, p. 774800, 2007. 